\title{
An Ethics of Inclusion: Recommendations for LGBTQI Research, Practice, and Training
}

\author{
Mallaigh McGinley, Sharon G. Horne \\ University of Massachusetts Boston, Boston, USA \\ *Corresponding author. E-mail: sharon.horne@umb.edu
}

Background. Throughout the last forty years, an emerging set of global norms addressing the rights and treatment of lesbian, gay, bisexual, transgender, queer, and intersex (LGBTQI) people have emerged and are continuing to evolve. This article will outline the trajectory of LGBTI concerns in the context of international human rights, and make a case for psychological ethics that are inclusive of concerns specific to sexual orientation, gender identity, and gender expression (SOGIE). These discussions will be framed in the context of the historical stigma and pathologization associated with SOGIE concerns, as well as the increasing global visibility and political and social organizing of LGBTQI communities.

Discussion. First, the rise of international and regional ethics codes pertaining to SOGIE concerns, including the role of the United Nations, will be reviewed. Second, recommendations for an ethical approach to psychological research, practice, training, and advocacy inclusive of SOGIE concerns will be discussed. These recommendations will be informed by the existing ethical framework of the European Federation of Psychologists' Associations (EFPA), and will address the unique concerns of sexual orientation minority populations; transgender, non-binary, and gender-expansive (TNG) people; and intersex populations. Finally, the International Psychology Network for LGBTI Issues (IPsyNet) will be introduced as a model for networking in support of SOGIE interests within LGBTQI-affirming national psychological organizations.

Conclusion. As European ethical practices respond to calls from human rights stakeholders for increased inclusion of SOGIE concerns, this paper proposes that it is the responsibility of international psychological practice to support the human rights of all global citizens.
Keywords:

Ethics; sexual orientation; gender identity; LGBTQI; human rights; sexual minority; gender minority; SOGIE; TNG 


\section{Introduction}

A recent review of international human rights law shows that throughout the last four decades, a set of global norms pertaining to the rights and treatment of lesbian, gay, bisexual, transgender, queer, and intersex (LGBTQI) people has emerged and continues to evolve (Baisley, 2016). These norms are the result of efforts across international governing bodies (particularly, the United Nation's Commission on Human Rights), civil society organizations (such as the International Lesbian, Gay, Bisexual, Trans and Intersex Association [ILGA]), and political advocacy groups within various countries that have taken strides toward increasing LGBTQI equality across the globe. These human rights defenders articulate the application of the agreed-upon human rights principles of universality, nondiscrimination, and equality to sexual orientation, gender identity, and gender expression (SOGIE) minority populations (Baisley, 2016; United Nations, 2016). These SOGIE-inclusive stances call for decriminalization of same-sex sexual behavior, and suggest that prohibitions against violence towards SOGIE minority populations have a basis in international law. They also maintain that the international community has a responsibility to address such violence and discrimination (Horne \& Manalastas, 2019).

The current landscape of proposed human rights standards, as they apply to SOGIE concerns and are related to mental health, is built upon the decisions by the World Psychiatric Association (WPA; Bhugra, Eckstrand, Levounis, Kar, \& Javate, 2016), the American Psychological Association (APA, 2012, 2015), and both the World Health Organization (WHO) and the American Psychiatric Association, to remove same-sex attraction from their lists of pathologies (American Psychiatric Association, 1980; WHO, 1992). Subsequently, they moved to destigmatize the distress experienced by transgender, non-binary, and gender expansive (TNG) people (American Psychiatric Association, 2013; WHO, 2018) in the two major psychiatric diagnostic and classification systems (ICD-11 and DSM-5). These expansions of international human rights so as to apply to SOGIE minority populations, highlight the important role which mental health practitioners and psychological organizations have played, and continue to play, in international efforts to achieve equity and safety for LGBTQI people.

However, in addition to these broad shifts within the European-Western psychological community from pathologization to an affirming and human rightsinclusive stance for SOGIE concerns, a multitude of national-level psychological organizations across the globe have made significant contributions to the rise of affirmative practice with SOGIE minority populations. Currently, psychological organizations on all continents (with the exception of Antarctica) have professional psychological organizations or committees with the explicit mission of addressing SOGIE concerns, and transnational collaboration on psychological approaches to LGBTQI populations continues to grow (Horne, Maroney, Nel, Chaparro, \& Manalastas, 2019).

This article will trace the development of LGBTI concerns as reflected in human rights platforms, and make a case for a SOGIE-inclusive ethics for psychology within the context of the historical pathologization of LGBTQI populations. First, the rise of international and regional ethics codes pertaining to SOGIE concerns, including the role of the United Nations, will be reviewed. Second, an ethical approach to psychological research, practice, training, and advocacy inclusive of 
SOGIE and LGBTQI concerns will be discussed, especially as informed by the ethical framework of the European Federation of Psychologists' Associations (EFPA). Finally, the International Psychology Network for LGBTI Issues (IPsyNet) will be introduced as a model, unique to the discipline of psychology, for networking in support of SOGIE interests within LGBTQI-affirming national psychological organizations.

\section{LGBTQI+ Visibility and Vulnerability}

Throughout the past five decades, the influence of globalization has sparked the rise of organized movements in support of SOGIE concerns across the globe, and led to increased demands for equality, inclusion, and safety for LGBTQI people (Horne, Maroney, Wheeler \& Peters, 2019). SOGIE concerns as such have often been characterized as distinctively Euro-Western (Horne \& White, 2019; Thoreson, 2014), and summarily rejected by non-Euro-Western governments (also referred to as majority countries), as Western imports (Judge, 2018; Nel, 2014). Such characterization of SOGIE concerns as exclusive to Euro-Western contexts has been proposed as a justification for harmful practices such as sexual orientation and gender identity change efforts (SOCE/GICE) within global anti-LGBTQI movements, spurred on by the argument that such practices will counterbalance undue Western influences (Horne \& McGinley, 2020).

However, this tension between the rise of LGBTQI activism and increased cultural scrutiny regarding the acceptance and inclusion of LGBTI rights, is not unique to the global expansion of SOGIE concerns. In effect, a standard of "normality" has historically been imposed as a criterion by which to measure and discipline forms of social deviance (Foucault, trans. 1977/1995; Warner, 2000). Therefore, an understanding of the mutual relationship between power and visibility shows that "abnormal" populations - in this case the LGBTQI population - are only vulnerable to cultural discipline when they become visible; indeed, the culture imposes a "compulsory visibility" (p. 187) in an effort to maintain disciplinary power (Foucault, 1977/1995).

With respect to SOGIE concerns, the manifestation of this striving toward normality has been increasingly differentially applied to LGBTI people and communities. Specifically, White, Western-European and North American, middle and upper income LGB - identified people have been granted greater approximations to "normality" through marriage equality, access to positions providing upward mobility, and other legal protections. In contrast, LGBTI people residing in nations where SOGIE identities and expressions are criminalized, marginalized, or tightly controlled, and "normality" is harder to achieve, particularly for ethnic and racial minorities, LB women and transgender/non-binary people, as well as low income individuals (Horne et al, 2019; Weber, 2018).

In the field of psychological practice, this process of re-pathologization can be observed in the expansion of sexual orientation change efforts and gender identity change efforts in the United States; took the form of organizations such as Exodus International, which emerged in response to the removal of homosexuality from the Diagnostic Statistical Manual in 1973 (Horne \& McGinley, 2020), and more recently, in the emergence of celibate identities, in which people identify as LGB but make clear that this identity does not include same-sex sexual relationships 
(Freeman-Coppadge \& Horne, 2019), and by mental health professionals offering treatment for mock diagnoses focused on obsessions about one's sexual orientation. Thus, the resistance to providing human rights has extended so far as to claim that identities intrinsic to SOGIE diversity can be forcibly altered via external psychological and behavioral change efforts (Horne \& Manalastas, 2019; Horne \& McGinley, 2020).

The pressures to conform to social norms have been influenced by Euro-Western medical and psychological science that historically has pathologized non-cisgender and non-heterosexual SOGIE, and placed increased pressure on SOGIE minority populations to assimilate to an imposed standard of normality as they become more visible in the culture at large (Warner, 2000). This pressure has contributed to the emergence of "post-gay" rhetoric, by which the most easily assimilable members of the LGBTQI community (typically cisgender, white gay and lesbian people of middle and upper income levels) are apt to abandon the queer liberation movement and pursue goals that approximate normalcy (e.g., marriage). Thus, they leave behind the less "normal" members of the community, such as TNG people, intersex populations, queer people of color, low income LGBTQI people, and people who live in countries where SOGIE concerns are strongly regulated (Horne \& White, 2019; Warner, 2000; Weber, 2018). In the global context, this tendency has contributed to a greater distinction between those who are "gay patriots" and those who become further marginalized (Weber, 2018), usually SOGIE minority members of non-Western cultures.

Within the United States, the contributions of major mental health organizations, including the American Psychological Association, in advocating for affirmative practices and inclusive treatment for LGBTI individuals has been pivotal in increasing mental health supports (APA, 2009, 2012, 2015; Horne \& McGinley, 2020; Gray, Haldeman \& Brinton, 2019). As organizing around SOGIE concerns continues to grow internationally, the role of psychological organizations in promoting the well-being of LGBTQI people must then be framed in the context of advocacy, and draw from human rights frameworks to increase attention toward minority groups within SOGIE communities. Western-based organizations in minority countries have historically dominated through prizing Euro-Western psychological teachings over indigenous approaches and forms of knowledge (Horne et al., 2019; Horne \& White, 2019; Thoreson, 2014), including national psychology organizations. Thus, these historically dominant organizations will need to engage in intentional power-sharing when collaborating with psychology organizations in majority countries in order to engage in advocacy and activism on behalf of LGBTI people and SOGIE concerns (Norsworthy \& Kaschak, 2013).

\section{An Overview of International and Regional Ethics Codes}

The inclusion of SOGIE concerns in international human rights discourse is relatively recent, as the push for the inclusion of sexual orientation and gender identity as protected identities has only gained traction since the mid-1990s (Horne \& Manalastas, 2019). Within the discipline of psychology, it is only since the 1970s that homosexuality ceased to be considered a mental disorder in dominant diagnostic frameworks (Drescher, 2015), and only since 2013 that gender diversity has 
begun to be de-pathologized in major diagnostic systems (Horne \& Manalastas, 2019). It is no surprise then that international human rights codes have similarly been slow to include SOGIE concerns.

\section{The United Nations}

The first time that sexual orientation was formally addressed at the United Nations was in 1982, in a case brought against Finland for censorship of media pertaining to homosexuality; the decision went in favor of Finland (Baisley, 2016). In 1993, a proposal to add sexual orientation to a United Nations resolution on the Prevention of Discrimination and Protection of Minorities failed to pass. Then in 1995, a move was made to add homosexual men to the list of protected categories under a United Nations resolution regarding non-discrimination based on HIV status (Sanders, 1996). When this proposal passed, it represented the first formal mention of homosexual people in a United Nations resolution.

Over the next several years, sexual orientation continued to garner more attention at the United Nations, including with an attempt by the International Gay and Lesbian Human Rights Commission (IGLHRC) to have sexual orientation declared as grounds for protection from discrimination at the 1995 Fourth World Conference on Women in Beijing (Girard, 2008). This measure was ultimately not included in the final draft (Horne \& Manalastas, 2019). However, the visible activism of lesbian and bisexual women at the conference was credited with maintaining a focus on sexual orientation concerns at the United Nations (Horne, 1996).

Despite the fact that SOGIE concerns lagged in recognition within the United Nations, the global community appears to have reached "a tipping point" in recognizing the validity of claims that SOGIE minorities need to be included in universal rulings on human rights law (Baisley, p. 137). Despite the inconsistent history of United Nations rulings on SOGIE concerns, Baisley (2016) emphasizes the importance of the legal foundation provided by United Nations decisions in generating new norms regarding the protection of LGBTQI populations across the globe.

This international shift in norms was evident in the passing of the first United Nations resolution explicitly addressing SOGIE concerns in 2011 by the Office of the United Nations High Commissioner for Human Rights (OHCHR; 2011), and the 2016 resolution on the "Protection against violence and discrimination based on sexual orientation, and gender identity." The latter represented the first time the United Nations mandated the appointment of an Independent Expert on SOGIE concerns, and included specific reference to intersex concerns (United Nations, 2016). Most recently, the United Nations Human Rights Council issued the first resolution pertaining to intersex populations, calling for the protection of human rights for women with "differences of sex development" (OHCHR, 2019). This development was in response to the international attention to the debate over naturally occurring testosterone levels in the case of female athlete Caster Semenya (“Caster Semenya," 2019).

Within the last decade, the United Nations has acknowledged the pervasive violence experienced by LGBT people internationally and issued a series of mandates which nation states are expected to uphold with regard to SOGIE concerns (OHCHR, 2012). These include a joint statement endorsed by 11 other United Na- 
tions agencies expressing concern about human rights violations faced by LGBTI people and their families (International Labour Organization [ILO] et al., 2015). These actions represented the culmination of many years of activism by and on behalf of the global LGBTQI community (Horne \& Manalastas, 2019). Over 190 countries have pledged to participate in the UN's Sustainable Development Goals for 2030, which emphasize a commitment to give priority to the most marginalized global citizens through non-discrimination and universal inclusion (Stuart \& Samman, 2017). Many countries are interpreting this goal as inclusive of SOGIE minorities (Horne \& Manalastas, 2019; O’Malley \& Holzinger, 2018).

\section{The Yogyakarta Principles}

Due to the historical irregularity of United Nations rulings on SOGIE concerns, an independent committee of transnational human rights experts, including academics, judges, United Nations experts, and NGO representatives, convened in Yogyakarta, Indonesia in November 2006 (Sanders, 2008). This meeting, co-organized by the International Service for Human Rights and the International Commission of Jurists (Sanders, 2008), produced an outline of how existing international legal principles could and should be applied to SOGIE concerns, a document now known as the Yogyakarta Principles (Horne \& Manalastas, 2019; International Service for Human Rights [ISHR] \& International Commission of Jurists [ICJ], 2007). These 29 principles were intended to move beyond an aspirational approach to human rights for SOGIE populations (Sanders, 2008), and clearly define State obligations under existing international human rights law to protect SOGIE minority populations. Thus the Principles represented an effort to affirm compulsory global legal standards for member States (ISHR \& ICJ, 2007).

This document argued that the standards set out by the United Nations $\mathrm{Hu}$ man Rights Commission and the Universal Declaration of Human Rights (United Nations General Assembly, 1948) applied to SOGIE concerns as to all human beings; thus, humans of any sexual orientation or gender identity are entitled to equal rights and dignity, including safety, privacy, and humane treatment. The document proposed as a directive that all United Nations bodies engaged in human rights decisions apply the stated principles in all future resolutions pertaining to SOGIE concerns (Horne \& Manalastas, 2019). In 2017, 10 additional principles were added (the revised Yogyakarta Principles Plus 10) to reflect and respond to developments in the field of international human rights law, and to better encapsulate the unique types of violations that may affect people due to "gender expression" and "sex characteristics" (ISHR \& ARC International, 2017, p.4).

\section{European Regional Psychology Ethics}

Although various national standards exist, the only regional code of psychological ethics at the time of this writing is that of the EFPA. The EFPA is an umbrella group comprised of 37 European psychological organizations; it represents approximately 300,000 psychologists in the European region (EFPA, 2017). The stated goals of the EFPA include promoting the psychological profession and improving clinical psychological practice. The EFPA sets the standards of education and professional training in psychology, as well as the ethical codes of conduct for inclusion in the 
Register of European Psychologists (EuroPsy, n.d.). It is explicitly dedicated to outlining psychologists' responsibilities to raise awareness of, prevention of, and response to global human rights violations (EFPA, n.d.-a).

The EFPA ethics codes highlight concerns pertaining to sexual orientation minorities, stating that sexual orientation should be included as a category under individual differences that warrant protection from discriminatory practice (EFPA, 2005). Despite the provision of a major addendum to its ethical codes in 2015, the EFPA has not expanded these classifications specifically to include transgender, gender diverse, and/or intersex populations; the term "gender" has not been elaborated upon since the original codes were drafted in 1995 (EFPA, 2005; 2015). Recommendations for the inclusion of TNG people in the field of psychology have highlighted the importance of differentiating gender identity from sexual orientation (Sandil \& Henise, 2017; Singh \& dickey, 2017), and of reflecting the "specialized language" endorsed by TNG people to describe their own experience (APA, 2015, p. 862). It is suggested that regional and psychological ethics codes reflect the particular mental health needs of these populations, and that ethics codes articulate the particular dimensions of experience (i.e., gender expression, sexual orientation, gender identity) and individuals and communities (i.e., LGBTQI) they intend their codes to inform treatment and inclusion of in psychological practice and research.

National psychological organizations have endorsed practice guidelines respecting sexual orientation and gender identity in several European countries (i.e., the British Psychological Society [BPS, 2012a; 2012b; 2019], the German Association of LGBTIQ People in Psychology [Wolf, Fünfgeld, Oehler, \& Andrae, 2015], the Hungarian Psychological Society [HPS, 2016], and the Psychological Society of Ireland [2015]). The absence of reference to broader gender and sexual diversity in the EFPA ethics code may also reflect a trend in which Euro-Western psychological organizations have historically been less focused upon inclusion of intersex concerns relative to LGBT issues than those in the Global South (Horne et al., 2019).

The perpetuation of a "homointernationalism," which symbolically extends human rights to those within LGBT populations who have greater privileges and access due to class, race, and/or nationality (i.e., those who can be assumed to fit expectations of normativity), can reinforce the "othering" of those who don't fit the narrative of the "gay rights holder." This category would include TNG and intersex people, as well as those with intersecting marginalized identities along racial, socioeconomic, or citizenship lines (Horne et al., 2019; Weber, 2018). It is recommended then that Euro-Western models of psychological ethical standards and advocacy ensure broad rights and supports pertaining to SOGIE and intersex concerns, in order to create an inclusive global LGBTQI citizenship (Horne et al., 2019; Horne \& Manalastas, 2020).

\section{A Framework for Psychological Advocacy: An Ethics of SOGIE Concerns within Psychology}

The EFPA Model Code of Ethics (2015) was designed with the intention that it be applied, along with the principles of the Meta Code of Ethics (2005), to guide psy- 
chological training and practice, including research, so as to ensure that European psychologists act appropriately and ethically. As these codes instruct psychologists to adhere to principles outlined by international human rights conventions (EFPA, 2015), it can be inferred that they should also be applied to the concerns of TNG and intersex populations, since these groups have been specifically highlighted in recent United Nations resolutions (UN, 2016; OHCHR, 2019).

The EFPA (2015) ethics code prescribes that psychologists respect the expertise of their clients and other relevant groups on the unique experiences of the cultural differences pertaining to client identities, with special attention to the protection of vulnerable populations and the clients' rights to self-determination. Thus, the EFPA ethics code, as well as the specific recommendations for best practices with LGBTQI populations, should consider the following recommendations to SOGIE concerns.

\section{Research Ethics}

A SOGIE/LGBTQI-inclusive approach to research would value the experiences of sexual and gender minorities and put a focus on their psychological experiences in the course of psychological exploration. For example, psychological survey research that collects age, ethnicity, and regional data would include categories for sexual orientation, gender identity, gender expression, and biological characteristics, which would validate the experiences of LGBTQI people, and could be used to test for similarities and differences with heterosexual and cisgender participants.

This approach coheres with what the Model Code of the EFPA describes in Point 2.i:

The practice of psychologists is based on science and reliable experience. Psychology and the psychological profession are in a continuous process of development, producing new and more complex knowledge and methods. Since social change continuously brings forth new problematic situations, it is important that psychologists pay attention to their own limitations and are able to turn to their colleagues and other professionals for additional knowledge and competence. (EFPA, 2015, p. 4)

A SOGIE-inclusive approach to applying this ethics code might include instituting guidelines for reviewing scientific articles that are inclusive of SOGIE classifications, or offering training on how to integrate SOGIE concerns into scientific research (e.g., researchers who expanded marital communication research to longterm same-sex partners revealed many new dimensions of relational experience in couples and important distinctions differing by gender and between other-sex and same-sex couples; e.g., Garanzini et al., 2017; Martell, Safren, \& Prince, 2004). A SOGIE-inclusive research ethics might offer perspectives on identity and shifts in terminology. Furthermore, it would demonstrate the importance of SOGIE-related evidence in psychological research. For example, over the past few decades, awareness the importance of SOGIE-related concerns in other psychological experiences has increased (e.g., parenting research; neurodiversity scholarship; career-related outcomes), whereas in the past the intersectionality of psychological experiences with SOGIE concerns may not have been apparent. 
Tremendous strides have been made in SOGIE measurement, and an LGBTQIinclusive research ethics would include contemporary assessment tools; numerous metrics are now available for measuring common constructs such as internalized stigma (e.g., Herek, Gillis, \& Cogan, 2009; Syzmanksi \& Chung, \& Balsam, 2001, among many others); attitudes toward LGBT people (e.g., Herek, 1998; Nagoshi et al., 2008; Worthington, Dillon, Becker-Schutte, 2005); and other constructs. Tebbe and Budge (2016) generated a set of recommendations for researchers planning and conducting research with TNG populations, including the need for new metrics and further psychometric validation of existing ones that are designed specifically to capture TNG experiences. Intersex advocacy groups have highlighted the need for community-based participatory research (CBPR) involving intersex advocates, clinicians, and researchers in collaborating to produce intersex-affirming research (interAct, 2016).

Competent intersex research demands practices that maximize inclusion of a range of intersex identities, would use measures and research designs that accurately reflect the unique experiences of intersex people, and would pose research questions regarding intersex quality of life (Liao, \& Simmonds, 2014). In addition, most of the measurements are created for English speakers, and have been developed through work with LGBTQI participants in the context of the United States. Creating a shared site for measures developed within Europe would be a useful addition to the resources available for European psychologists. One other way to put a focus on SOGIE-related research is to provide awards in the areas of LGBTQI-research.

\section{Practice Ethics}

A SOGIE-inclusive practice ethics would incorporate the need for interventions and clinical awareness for the particular needs of LGBTQI clients, including their experiences of sexual and gender diversity. This includes consideration of specific stressors which LGBTQI individuals experience as a result of their identities, and the ways in which these stressors impact mental health, as well as attention to identity-specific resiliencies that can be fostered in the therapeutic relationship (Meyer, 2003). Emerging evidence-based treatments that incorporate a minority stress framework (Meyer, 2003) in addressing mental health concerns for LGB people may provide an avenue for clinical adaptation of LGB-affirming treatment guidelines (Pachankis, Hatzenbuehler, Rendina, Safren, \& Parsons, 2015). These SOGIEinclusive practices would develop appropriate clinical interventions not only for LGBTQI individuals, but for couples and families, particularly, in areas of the world where LGBTI concerns remain invisible.

Recent recommendations for increasing mental health practitioners' competence in working with TNG clients include the following practices: 1) developing increased awareness of gender identities and personal gender biases; 2) seeking training and advanced coursework specifically designed to increase TNG-competence; 3) creating an environment that maintains safety and supportiveness for TNG people; 4) acknowledging the impact of systemic transphobia and cisnormativity; 5) moving beyond gatekeeping and acknowledging TNG clients as the experts on their own experience; and 6) engaging in advocacy and consultation 
work to advance TNG rights outside the counseling space (Sandil \& Henise, 2017; Singh \& dickey, 2017).

Scholars have called for the development of interventions designed to increase resilience for TNG people at both the group and individual level, highlighting the ways in which resilience can counteract the negative impact of TNG-specific minority stressors (Levitt, Collins, Roberts, Maroney, Wadler, 2020; Matsuno \& Israel, 2018; Maroney, 2020; Puckett \& Levitt, 2015). Clinicians are advised to consider how TNG-specific experiences, such as the desire for gender affirmation, impact health and risk behavior in the context of social oppression and intersecting marginalized identities (Sevelius, 2013).

Historically, intersex concerns have been overlooked in identity-affirming clinical approaches within the field of psychology. Intersex advocacy groups recommend that intersex children and adults be provided honest and accurate information about intersex identities and concerns, and have access to intersex-affirming psychological counseling (e.g., Intersex Society of North America, 2008; Organisation Intersex International Europe 2013; 2014; 2017).

Within the field of psychology, researchers have suggested that psychologists utilize findings from emerging evidence-based practices from values-based medicine, as well as from professional ethics codes, in treating intersex people, including the mandate to pursue interventions that generate increased well-being and promote agency along lines of diversity and equality (Liao, \& Simmonds, 2014). An LGBTQI-inclusive practice ethics would acknowledge decades of research suggesting that for many LGBT people, sexual orientation and gender identity awareness often occurs at an early age, and therefore, limiting the information, as well as psychological resources, available to youth runs counter to ethical and effective practice.

\section{Training Ethics}

Ongoing training in the evolving needs of LGBTQI populations is crucial to the continued expansion of the aforementioned ethical research and practice standards. Since supervision is a key component of a psychologist's training, mental health professionals acting in a clinical supervisory role with graduate students are recommended to provide ongoing assessment of trainees' competency in working with LGBT clients (Walker \& Prince, 2010). Supervisors are encouraged to support students in increasing awareness of SOGIE concerns by directing them to appropriate guidelines for practice with LGBT populations; and to prevent trainees from causing potential harm to LGBT clients by assessing the appropriateness of the client/trainee therapeutic match (Walker \& Prince, 2010).

Although many psychology graduate students and practicing psychologists report providing therapy services to TNG people, a much lower percentage of professionals self-report that they are competent in working with TNG clients (APA, 2009). Training recommendations (Walker \& Prince, 2010) for increasing competence in working with TNG clients include the following: a commitment to ongoing education regarding gender identity concerns, including issues of power in the counseling relationship; consideration of other contextual factors, in addition 
to gender identity, that contribute to the client's distress; and familiarity with the World Professional Association for Transgender Health Standards of Care (Coleman et al., 2011).

Training remains an area for growth in generating increased competence for practitioners working with intersex populations. The goal of training psychologists in intersex-affirming practices has been identified by intersex activist groups as a necessary component in securing human rights for these populations (Astraea Foundation, n.d.). Although the EFPA provides a holistic set of standards for psychological training (EFPA, n.d.-b), these standards would be strengthened by highlighting the need for competence in, and awareness of, diverse identities and the concerns specific to minority groups, such as the LGBTQI communities.

\section{The International Psychology Network for LGBTI Issues}

Launched in 2005 following an international meeting of LGBT psychologists in San Francisco in 2001 (International Meeting on Lesbian, Gay, and Bisexual Concerns in Psychology, 2003), the International Psychology Network for LGBTI Issues (IPsyNet) is unique within the discipline of psychology. The membership of IPsyNet currently includes 23 national psychological organizations that collaborate to promote psychological knowledge about LGBTI concerns, and advocate for the human rights and well-being of sexual and gender minority people transnationally. Current European members include the British Psychological Society, the German Association of LGBTIQ in Psychology, the Hungarian Psychological Society, the Psychological Society of Ireland, the Russian Psychological Society, the Spanish Psychological Association, and the Turkish Psychological Association.

IPsyNet members have collaborated on advocacy efforts (e.g., the 2014 joint letter to President Museveni of Uganda in protest of a proposed draconian anti-homosexuality bill); supported the development of indigenous LGBTI statements and guidelines; and promoted the dissemination of LGBTI research and knowledge. In 2018 IPsyNet members, drawing from extant transnational international human rights frameworks, drafted and endorsed the IPsyNet Statement and Commitment on LGBTI Issues-a psychology-based human rights position paper which affirmed sexual orientation, gender identity, and intersex concerns (https://www. apa.org/ipsynet/advocacy/policy/statement-commitment). Thus far, the Statement and Commitment on LGBTI Issues has been endorsed by 31 national psychological organizations from all areas of the world, and has been translated into 10 languages (IPsyNet, 2018).

Specifying mutual transnational values of organized psychology, as well as an emerging global consensus on inclusion of LGBTI concerns within human rights as grounded in psychological science concerning sexual and gender minority people, the IPsyNet statement seeks to inform practice, training, and policy in psychology. Given the lack of specification on LGBTI concerns in psychology ethics codes, the IPsyNet Statement can serve as a complementary guide to considering LGBTI concerns as they relate to research, practice, training, and advocacy. IPsyNet (https:// www.apa.org/ipsynet/index) also provides a resource for emerging interest in LGBTI concerns in psychological organizations around the world. 


\section{Conclusion}

As the evolution of European ethical practices moves toward increasing inclusion of SOGIE concerns, in accordance with the emerging global human rights discourse, these recommendations and the proposed frameworks may serve as valuable resources to that end. The EFPA expects that all practicing psychologists in Europe, regardless of EFPA membership or country of practice, adhere to the Meta and Model codes of ethics, with the goal of a unified ethical practice across the continent by 2030 (EFPA, 2015). This mandate suggests that all European psychologists should work towards greater inclusion of SOGIE concerns across the areas of research, practice, and training, including engaging in advocacy work to such ends.

As the field of psychology continues to depathologize LGBTQI identities and progresses toward an ethos of universality, nondiscrimination, and equality (Baisley, 2016), it is the responsibility of international and regional psychological organizations to support the human rights of all global citizens (Horne et al., 2019) .

\section{References}

American Psychiatric Association. (1980). Diagnostic and statistical manual of mental disorders (3rd ed.). Washington, DC, USA: American Psychiatric Press.

American Psychiatric Association. (2013). Diagnostic and statistical manual of mental disorders (5th ed.). Washington, DC, USA: American Psychiatric Press. https://doi.org/10.1176/appi.books.9780890425596

American Psychological Association. (2009). Resolution on appropriate affirmative responses to sexual orientation distress and change efforts. Retrieved from http:// www.apa.org/about/governance/ council/policy/sexual-orientation.aspx

American Psychological Association. (2012). Guidelines for psychological practice with lesbian, gay, and bisexual clients. The American Psychologist, 67(1), 10-42. https://doi.org/10.1037/a0024659

American Psychological Association. (2015). Guidelines for psychological practice with transgender and gender nonconforming people. American Psychologist, 70(9), 832-864. https://doi.org/10.1037/a0039906

American Psychological Association, Task Force on Gender Identity and Gender Variance. (2009). Report of the task force on gender identity and gender variance. Washington, DC: American Psychological Association.

Baisley, E. (2016). Reaching the tipping point? Emerging international human rights norms pertaining to sexual orientation and gender identity. Human Rights Quarterly, 38(1), 134-163. https://doi.org/10.1177/0891243207306384

Bhugra, D., Eckstrand, K., Levounis, P., Kar, A., \& Javate, K.R. (2016). WPA position statementongender identity and same-sex orientation, attraction, and behaviours. https://doi.org/10.1002/wps.20340/

British Psychological Society. (2012a). Guidelines and literature review for psychologists working therapeutically with sexual and gender minority clients. Retrieved from https://www.bps.org.uk/newsand-policy/guidelines-and-literature-review-psychologists-working-therapeuticallysexual-and

British Psychological Society. (2012b, December). Position statement: Therapies attempting to change sexual orientation. Retrieved from https://www.bps.org.uk/news-and-policy/bps-position-statement-therapies-attemptingchange-sexual-orientation-2013

British Psychological Society. (2019). Guidelines for psychologists working with gender, sexuality and relationship diversity. Retrieved from https://www.bps.org.uk/sites/bps.org.uk/files/Policy/Policy\%20-\%20Files/Guidelines\%20for\%20psychologists\%20working\%20with\%20gender\%2C\%20 sexuality\%20and\%20relationship\%20diversity.pdf

Caster Semenya unquestionably a woman, say her lawyers before court case against IAAF (2019, February 14). BBC Sport. Retrieved from https://www.bbc.com/sport/athletics/47244017 
Coleman, E., Bockting, W., Botzer, M., Cohen-Kettenis, P., DeCuypere, G., Feldman, J., ... Zucker, K. (2011). Standards of care for the health of transsexual, transgender, and gendernonconforming people (Version 7). International Journal of Transgenderism, 13, 165-232. https://doi.org/10.1080/15532739.2011.700873

Drescher, J. (2015). Out of DSM: Depathologizing homosexuality. Behavioral Sciences, 5, 565-575. https://doi.org/10.3390/bs5040565

European Federation of Psychologists' Associations. (n.d.-a). EFPA's role regarding 'human rights.' Retrieved from http://human-rights.efpa.eu/

European Federation of Psychologists' Associations. (n.d.-b). Training standards for psychologists specializing in psychotherapy. Retrieved from http://www.efpa.eu/professional-development/training-standards-for-psychologists-specializing-in-psychotherapy

European Federation of Psychologists' Associations. (2005). Meta-code of ethics. Retrieved from http://ethics.efpa.eu/metaand-model-code/meta-code/

European Federation of Psychologists' Associations. (2015). Model-code of ethics. Retrieved from http://ethics.efpa.eu/metaand-model-code/model-code/

European Federation of Psychologists' Associations. (2017). About. Retrieved from http://www.efpa.eu/about

EuroPsy. (n.d.). Quality and standards. Retrieved from https://www.europsy.eu/quality-and-standards

Foucault, M. (1995). Discipline \& Punishment (A. Sheridan, Trans.). New York, NY: Second Vintage Books. (Original work published 1977).

Freeman-Coppadge, D.J., \& Horne, S.G. (2019). "What happens if the cross falls and crushes me?": Psychological and spiritual promises and perils of lesbian and gay Christian celibacy. Psychology of Sexual Orientation and Gender Diversity, 6(4), 486-497. https://doi.org/10.1037/sgd0000341

Garanzini, S., Yee, A., Gottman, J., Gottman, J., Cole, C., Preciado, M., \& Jasculca, C. (2017). Results of Gottman Method Couples Therapy with gay and lesbian couples. Journal of Marital and Family Therapy, 43(4), 674-684. https://doi.org/10.1111/jmft.12276

Girard, F. (2008). United Nations: Negotiating sexual rights and sexual orientation at the UN. Retrieved from http://www.sxpolitics.org/frontlines/book/pdf/sexpolitics.pdf

Herek, G.M. (1998). The Attitudes Toward Lesbians and Gay Men (ATLG) scale. In C.M. Davis, W.L. Yarber, R. Bauserman, G. Schreer, \& S.L. Davis (Eds.), Handbook of sexuality-related measures (pp. 392-394). Thousand Oaks, CA: Sage Publications

Herek, G.M., Gillis, J.R., \& Cogan, J.C. (2009). Internalized stigma among sexual minority adults: Insights from a social psychological perspective. Journal of Counseling Psychology, 56(1), 32-43. https://doi.org/10.1037/a0014672

Horne, S.G. (1996). Group therapy in the appointed restaurant: Reflections from Beijing. Feminist Family Therapy, 8(4), 47-56. https://doi.org/10.1300/J086v08n04_05

Horne, S.G., \& Manalastas, E. (in press). Psychology and the global human rights agenda on sexual orientation and gender identity. In N. Rubin \& R. Flores (Eds.), The Cambridge Handbook of Psychology and Human Rights. Cambridge, U.K.: Cambridge University Press.

Horne, S.G., Maroney, M.R., Nel, J.A., Chaparro, R.A., \& Manalastas, E.J. (2019). Emergence of a transnational LGBTI psychology: Commonalities and challenges in advocacy and activism. American Psychologist, 74(8), 967. https://doi.org/10.1037/amp0000561

Horne, S.G., Maroney, M.R., Wheeler, E., \& Peters, S. (2019). The psychological development of LGBTQ activists. Unpublished manuscript.

Horne, S.G., \& McGinley, M. (2020). A global export, a local commodity: SOCE/GICE in international contexts. In D. Haldeman \& M. Hendricks (Eds.), Sexual Orientation and Gender Identity Change Efforts. New York, NY: Harrington Park Press.

Horne, S.G., \& White, L. (2019). The return of repression: Mental health concerns of Lesbian, Gay, Bisexual, and Transgender People in Russia. In N. Nakumura \& C. Logie (Eds.), LGBT Mental Health: Global Perspectives and Experiences. Washington, DC: American Psychological Association. https://doi.org/10.1037/0000159-006

Hungarian Psychological Society. (2016). A guide to psychological work with LGBT and gender nonconforming clients: Translation of the APA LGB and Transgender and Gender Non-Conforming 
guidelines. Retrieved from http://mpt.hu/wp-content/uploads/2016/12/MPT_APATerapiasUtmutato.pdf

interAct. (2016, September 29). Official interACT policy on participation in research. Retrieved from https://interactadvocates.org/interact-policy-on-participation-in-research/

ILO, OHCHR, UNDP, UNESCO, UNFPA, UNHCR, UNICEF, UNODC, UN Women, WFP, WHO, \& UNAIDS. (2015). Joint UN statement on ending violence and discrimination against lesbian, gay, bisexual, transgender and intersex people. Retrieved from: https://www.ohchr.org/en/issues/discrimination/pages/jointlgbtistatement.aspx

International Meeting on Lesbian, Gay, and Bisexual Concerns in Psychology. (2003). Sexual orientation and mental health: Toward global perspectives on practice and policy. Retrieved from https:// www.apa.org/pi/lgbt/resources/international-meeting.pdf

International Service for Human Rights and ARC International. (2017). The Yogyakarta Principles Plus 10: Additional principles and state obligations on the application of international human rights law in relation to sexual orientation, gender identity, gender expression and sex characteristics to complement the Yogyakarta Principles. Retrieved from https://yogyakartaprinciples.org/

International Service for Human Rights \& International Commission of Jurists. (2007). The Yogyakarta Principles: Principles on the application of international human rights law in relation to sexual orientation and gender identity. Retrieved from http://yogyakartaprinciples.org/wp-content/uploads/2016/08/principles_en.pdf

Intersex Society of North America. (2008). Frequently asked questions. Retrieved from https://isna. org/faq/printable/

International Psychology Network for Lesbian, Gay, Bisexual, Transgender and Intersex Issues. (2018). IPsyNet statement on LGBTQ+ concerns. Retrieved from https://www.apa.org/ipsynet/advocacy/policy/statement-english.pdf

Judge, M. (2018). Blackwashing homophobia: Violence and the politics of sexuality, gender and race. Cape Town: Routledge. https://doi.org/10.4324/9781315735368

Liao, L.M., \& Simmonds, M. (2014). A values-driven and evidence-based health care psychology for diverse sex development. Psychology \& Sexuality, 5(1), 83-101. https://doi.org/10.1080/19419899.2013.831217

Levitt, H.M., Collins, K., Roberts, T., Maroney, M.R. \& Wadler, B. (2020). Healing from heterosexism through expressive writing interventions. Manuscript in preparation. University of Massachusetts Boston, Boston, MA.

Maroney, M.R. (2020). Exploring the efficacy of an online intervention in processing experiences of heterosexism among autistic-LGBTQ individuals (Unpublished doctoral dissertation). University of Massachusetts Boston, Boston, MA.

Martell, C.R., Safren, S.A., \& Prince, S.E. (2004). Cognitive-behavioral therapies with lesbian, gay, and bisexual clients. New York, NY: Guilford Press.

Matsuno, E., \& Israel, T. (2018). Psychological interventions promoting resilience among transgender individuals: Transgender resilience intervention model (TRIM). The Counseling Psychologist, 46(5), 632-655. https://doi.org/10.1177/0011000018787261

Nagoshi, J.L., Adams, K.A., Terrell, H.K., Hill, E.D., Brzuzy, S., \& Nagoshi, C.T. (2008). Gender differences in correlates of homophobia and transphobia. Sex roles, 59(7-8), 521-531. https://doi.org/10.1007/s11199-008-9458-7

Nel, J.A. (2014). South African psychology can and should provide leadership in advancing understanding of sexual and gender diversity on the African continent. South African Journal of Psychology, 44, 145-148. https://doi.org/10.1177/0081246314530834

Norsworthy, K., \& Kaschak, E. (2013). Global border crossings: Feminist activists and peace workers collaborating across cultures. New York, NY: Routledge. https://doi.org/10.4324/9780203720370

Puckett, J.A. \& Levitt, H.M. (2015). Internalized stigma within sexual and gender minorities: Change strategies and clinical implications. Journal of LGBT Issues in Counseling, 9, 329-349. https://doi.org/10.1080/15538605.2015.1112336

O’Malley, J., \& Holzinger, A. (2018). Sexual and gender minorities and the Sustainable Development Goals. United Nations Development Programme. Retrieved from http://www.undp.org/content/ undp/en/home/librarypage/hiv-aids/sexual-and-gender-minorities.html 
Office of the United Nations High Commissioner for Human Rights (2011). Discriminatory laws and practices and acts of violence against individuals based on their sexual orientation and gender identity. Retrieved from https://www.ohchr.org/documents/issues/discrimination/a.hrc.19.41_english.pdf

Office of the United Nations High Commissioner for Human Rights (2012). Born free and equal: Sexual orientation and gender identity in international human rights law. Retrieved from https://www.ohchr.org/en/issues/discrimination/pages/bornfreeequalbooklet.aspx

Office of the United Nations High Commissioner for Human Rights (2019). Elimination of discrimination against women and girls in sport. Retrieved from ILGA website: https://ilga.org/downloads/Elimination_of_discrimination_against_women_and_girls_in_sport.pdf

Organisation Intersex International Europe. (2013, December 1). Malta declaration. Retrieved from https://oiieurope.org/malta-declaration/

Organisation Intersex International Europe. (2014, October 8). Statement of Riga. Retrieved from https://oiieurope.org/statement-of-riga/

Organisation Intersex International Europe. (2014, March 31). Statement of the 1st European Intersex Community Event. Retrieved from https://oiieurope.org/statement-1st-european-intersex-community-event-vienna-30st-31st-march-2017/

Pachankis, J.E., Hatzenbuehler, M.L., Rendina, H.J., Safren, S.A., \& Parsons, J.T. (2015). LGBaffirmative cognitive-behavioral therapy for young adult gay and bisexual men: A randomized controlled trial of a transdiagnostic minority stress approach. Journal of Consulting and Clinical Psychology, 83(5), 875-889. https://doi.org/10.1037/ccp0000037

Psychological Society of Ireland. (2015). Guidelines for good practice with lesbian, gay and bisexual clients. Retrieved from https://www.psychologicalsociety.ie/source/PSI\%20Guidelines\%20for\%20 Good\%20Practice\%20with\%20LGB\%20Clients_1.pdf

Sanders, D. (1996). Getting lesbian and gay issues on the international human rights agenda. Human Rights Quarterly, 18(1), 67-106. https://doi.org/10.1353/hrq.1996.0010

Sanders, D. (2008). The role of the Yogyakarta Principles. International Gay and Lesbian Human Rights Commission, 1-9.

Sandil, R., \& Henise, S. (2017). Making psychology trans-inclusive and trans-affirmative: Recommendations for research and practice. In R. Ruth \& E. Santacruz (Eds.), LGBT psychology and mental health: Emerging research and advances (pp. 47-68). Santa Barbara, CA: Praeger.

Sevelius, J.M. (2013). Gender affirmation: A framework for conceptualizing risk behavior among transgender women of color. Sex roles, 68(11-12), 675-689. https://doi.org/10.1007/s11199-012-0216-5

Singh, A.A. \& dickey, l.m. (Eds.). (2017). Affirmative counseling and psychological practice with transgender and gender nonconforming clients. Washington, DC: American Psychological Association. https://doi.org/10.1037/14957-000

Stuart, E., \& Samman, E. (2017). Defining 'leave no one behind.' Overseas Development Institute. Retrieved from http://www.odi.org/sites/odi.org.uk/files/resource- documents/11809.pdf

Tebbe, E.A., \& Budge, S.L. (2016). Research with trans communities: Applying a process-oriented approach to methodological considerations and research recommendations. The Counseling Psychologist, 44(7), 996-1024. http://doi.org/10.1177/0011000015609045

Thoreson, R.R. (2014). Transnational LGBT activism: Workingfor sexual rights worldwide. Minneapolis, MN: University of Minnesota Press. https://doi.org/10.5749/minnesota/9780816692712.001.0001

United Nations. (2016). Resolution adopted by the Human Rights Council: Protection against violence and discrimination based on sexual orientation and gender identity. Retrieved from http://www.un.org/en/ga/search/view_doc.asp?symbol=A/HRC/RES/32/2

United Nations General Assembly. (1948). Universal Declaration of Human Rights. Retrieved from http://www.refworld.org/docid/3ae6b3712c.html

Walker, J.A., \& Prince, T. (2010). Training considerations and suggested counseling interventions for LGBT individuals. Journal of LGBT Issues in Counseling, 4(1), 2-17. https://doi.org/10.1080/15538600903552756

Warner, M. (2000). The trouble with normal: Sex, politics, and the ethics of queer life. Cambridge, MA: Harvard University Press. 
Weber, C. (2018). Queer international relations: Sovereignty, sexuality and the will to knowledge. New York, N.Y.: Oxford University Press.

Wolf, G., Fünfgeld, M., Oehler, R. \& Andrae, S. (2015). Empfehlungen zur Psychotherapie und Beratung mit lesbischen, schwulen und bisexuellen Klientinnen (Recommendations for psychotherapy and counselling with LGB clients). Verhaltenstherapie \& psychosoziale Praxis, 47, 21-48. http://dx.doi.org/10.17194/vlsp.2015.4

World Health Organization. (1992). The ICD-10 classification of mental and behavioural disorders: Clinical descriptions and diagnostic guidelines. Geneva: World Health Organization.

World Health Organization. (2018). International classification of diseases for mortality and morbidity statistics (11th ed.). Retrieved from https://icd.who.int/browse11/l-m/en

Worthington, R.L., Dillon, F.R., \& Becker-Schutte, A.M. (2005). Development, reliability, and validity of the Lesbian, Gay, and Bisexual Knowledge and Attitudes Scale for Heterosexuals (LGB-KASH). Journal of Counseling Psychology, 52, 104-118. https://doi.org/10.1037/0022-0167.52.1.104

Original manuscript received October 12, 2019

Revised manuscript accepted December 24, 2019

First published online March 15, 2020

To cite this article: McGinley, M., Horne, S.G. (2020). An Ethics of Inclusion: Recommendations for LGBTQI Research, Practice, and Training. Psychology in Russia: State of the Art, 13(1), 54-69. DOI: 10.11621/pir.2020.0106 